\title{
On the sustainable management of the Gulf of California
}

\author{
O. Arizpe $^{1} \&$ P. Muñoz ${ }^{2}$ \\ ${ }^{1}$ Universidad A. de Baja California Sur, Mexico \\ ${ }^{2}$ Instituto Politécnico Nacional, CIEMAD, Mexico
}

\begin{abstract}
The Gulf of California is known worldwide for its high and exclusive biological diversity, both terrestrial and marine, framed in a region of great scenic beauty. This beauty is shaped by coastal plains, cliffs, bays and lagoons, islands and islets, and its narrow but deep sea. During the twentieth century, this area was affected by increased human activity along the coastal strip, development and growth of industrial and artisanal fishing, agroindustrial development along the coastal plains and deltas of the main rivers, and urban and tourism growth. All of these factors endanger or threaten part of this great biological richness. Although during the 1995-2000 administration, the Mexican Environmental Program incorporated the Gulf of California as a priority area of marine resources and coastal ecosystems, according to an analysis in the recent National Development Plan, for a long time developmental strategies and policies in Mexico underestimated important aspects. Since 1997, the Mexican Environmental Ministry has promoted the execution of several environmental planning instruments in the gulf region. On 2001 and 2008, the Environmental Program emphasized that the ecological ordinance, in its modality or scale, must be the basis of sustainable development, determining the density and intensity of activities and ways of land use, as well as the areas to be preserved and restored. As part of these efforts, the first Marine Ecological Ordinance was developed in Mexico (2007), in the Gulf of California region. The main purpose of this planning process is to propose a holistic strategy for the region in a 1:250 000 scale, and local models for territorial ecological ordinances that would regulate and encourage land use and productive activities in the areas of interest. These models would be under a productive-diversification outline with specific guidelines for the management of natural resources. Their perspective would be one of compatibility between the use, conservation, and protection of natural resources and an increase in the local population quality of life to achieve a sustainable use of the territory natural resources in this complex and important area.
\end{abstract}

Keywords: Gulf of California, planning and management, marine ecological ordinance, marine and coastal development, land use. 


\section{Introduction}

Environmental policies include all of society's laws and agencies that deal with the environment. These policies - local, state, and federal - include measures for preventing or diminishing air and water pollution, as well as measures related to the use of natural resources Nebel and Wright [1] However, in democratic societies, the final responsibility of environmental policies falls on the citizens, not on the "authorities." The purpose of every environmental measure is to promote the common good. What that common good consists of might be a topic of controversy, but the improvement of the common well-being is undoubtedly of fundamental concern. The key to solving problems resulting from economic activities is the deliberate implementation of efficient policies and institutions. When this does not occur, the inevitable result is the degradation of the environment.

\section{Mexican environmental policies}

According to an analysis in the National Development Plan (Plan Nacional de Desarrollo (PND)) 2001-2006, [2] for a long time developmental strategies and policies in Mexico underestimated important aspects, including 1) the high population growth rate; 2) the inadequate population distribution in Mexico due to the expectation of urban employment; 3) expulsion of the labour force from primary activities; 4) national development founded on the country's rich natural resources; 5) economic and social costs of population growth; 6) the impact of productive activities and urbanization on the quality of air, water, and land; and 7) the implications of the degradation and destruction of natural resources with regard to the social welfare and economic development expectations. During the second half of the twentieth century, this scenario resulted in inadequate planning and erroneous decisions by politicians, who also allowed the almost insatiable exploitation of forests, pastures, and mineral deposits. The development model that has been followed in Mexico since the nineteenth century has not been able to stop the depletion of natural resources nor to reverse environmental deterioration caused by productive activities and urban population growth. On the contrary, the model has intrinsically aggravated these problems, paying them marginal attention that is isolated from the major national political decisions. However, at the end of the 1990s, specifically when the National Development Plan (1995-2000) emerges, the design of a clear environmental policy begins in Mexico. This policy proposes, among other objectives, to halt the tendencies toward environmental deterioration, to induce sustainable development, and to guarantee controlled access to natural resources that facilitates the fight against poverty and prevents the depletion of these resources. In addition, the PND 2001-2006 has proposed the following vision for Mexico in 2005: "...a fully democratic nation with a high quality of life that has been able to reduce extreme social imbalances and which will offer its citizens opportunities for integral human development and coexistence based on respect for the law and in the true exercise of human rights. It will be a dynamic nation, 
with worldwide leadership, with stable and competitive growth, and with an inclusive development that is balanced with the environment. It will be a nation proudly sustained in its roots, multiethnic, and multicultural, with a profound sense of national unity" (Plan Nacional de Desarrollo 2001-2006).

The National Development Plan establishes sustainability as one of its 12 fundamental principles. From now on, development must be clean, preserve the environment, and rebuild ecological systems until it achieves harmony among humans themselves and with nature. One major area that has been excluded from the development process and the forming of the Mexican nation is the protection of nature. Nature has not been adequately valued. For a long time, it has been depredated and contaminated without consideration. Thus, development must be based on life; otherwise, it would not be sustainable with relation to the country that is desired. The pressure on natural resources is rapidly increasing. The effect on ecosystems is notably manifested in the loss of species and in the disappearance, fragmentation, and degradation of habitats, landscapes, and ecosystems. This is the scenario where wild species dwell and, in most cases, tend to become extinct. Occasionally, they become plagues or vectors of these or other diseases. Also, current technology allows the manipulation of genetic material and the production of organisms that would not have existed naturally. However, to date there is no adequate international legislation that regulates this production, nor are its potential ecological effects known. This devastation process must be stopped. On this issue, solid scientific knowledge that supports the sustainable use of genes, species, and ecosystems is crucial in decision making that favors the conservation of biodiversity. As a first step to effect sustainability in national plans and policies, the federal executive government decided to incorporate the Commissions for Growth with Quality, Order, and Respect into the Secretariat of Environment and Natural Resources (Secretaría de Recursos Naturales-SEMARNAT). These commissions in turn, maintain their participation in the Commission for Social Development. Thus, SEMARNAT is in an exceptional position to participate and influence Mexico's main economy decisions. Sustainable development is a dynamic process in which several factors should strengthen the options to meet the people's basic needs and improve their quality of life. These factors include the management of natural resources, empowerment of human beings and cultural values, information mechanisms and citizen participation, scientific and technological development approach, formulation of new legal and administrative plans, the direction of the economy, and the adoption and incorporation of ethical principles regarding environmental responsibilities.

In prospective terms, the objective is to integrate the concepts of economic development and the protection of the environment. The strategy for sustainable development should be founded on the generation of basic conditions that allow the compatibility - in a context of social and economic equity - between Mexico's economic growth process and the protection of the environment and sustainable use of natural resources. Within this framework, SEMARNAT must play a leading role as promoter of Mexico's development conditions. In addition, it must protect the natural resources from possible destruction, recover them or 
demand that they be recovered, in every case that deals with activities within its jurisdiction. The main criterion for environmental and territorial management should be the prevention of possible impacts on the environment. In consequence, SEMARNAT must be capable of measuring, through Environmental Impact Statements (EIA), the implicit costs of preliminary plans and projects with regard to environmental and territorial aspects with the purpose of making them explicit and incorporating them into investment decisions. The valuation of environmental quality should be recognized in the social scope within the principle of sustainability, not only as an eminently technical issue, but as a process of collective and participative decisions.

\subsection{Mexico's new environmental policy}

According to the National Development Plan 2001-2006, sustainability is the main core that governs the Mexican government's new environmental policy. SEMARNAT will continue to be responsible for formulating, agreeing upon, and implementing Mexico's environmental policies. The formulation and implementation of strategies to achieve sustainable development will be a shared responsibility among institutions and agencies that determine the country's economic and social policies, with technical support from SEMARNAT. The main principles of this new environmental policy in Mexico are: Integrality, Intersectorality, Federalism, Inclusive and fair participation, Social and economical valuation of natural resources and Information access. Integrality is meant as the inclusion of economic, social, and environmental aspects of sustainability. Intersectorality includes the protection and conservation of the environment as strategic ingredients of the federal government's national plans and policies for the different economic and social sectors. The federalist aspect of sustainability seeks - through respectful relations and dialogue between federal and state authorities - to formulate a joint and coordinated action so that local environmental management is the main responsibility of state authorities. Inclusive and fair participation consists of promoting and propitiating the intervention of the entire citizenry in the design and implementation of environmental policies. This intervention must consider that all citizens are equal under the law. As such, they have the same opportunities to develop, regardless of their economic differences, political opinions, gender, religion, ethnicity, and sexual preferences, among others.

The valuation of natural resources has two components: economic and social. Natural resources will be best protected is this valuation is acknowledged, as well as the danger of their scarcity and their importance to society. Access to information is understood as the government's obligation and the right of every citizen to know about the environment's conditions, the causes of environmental degradation, and the consequences that this degradation has or could have on the population's health and well-being. The main principles of sustainability set the guidelines so that the design and implementation of Mexico's environmental policy are in compliance with the basic standards stipulated in the National Development Plan, which are legality, democratic governance, federalism, transparency, and accountability. The achievements of Mexico's environmental 
programs include progress in the territory's ecological ordinance, creation of a specific normative framework, increased citizen participation, and increased government interest in confronting environmental problems, thus adapting general government policies to sustainable development. Other factors that are just as important are biodiversity prioritization in natural resources conservation and management programs, significant progress in the consolidation of the National System of Natural Protected Areas, detection of critical environmental areas, and initiation of actions conducive to addressing these areas, with increased monitoring of environmental programs.

\subsection{Policies in the Gulf of California}

The Gulf of California is known worldwide for its varied and exclusive biological diversity, both terrestrial and marine, framed in a region of great scenic beauty. This beauty if is shaped by coastal plains, cliffs, bays and lagoons, islands and islets, and its narrow but deep sea. During the twentieth century, this area was affected by increased human activity along the coastal strip, development and growth of industrial and artisanal fishing, agroindustrial development along the coastal plains and deltas of the main rivers, and urban and tourism growth. All of these factors endanger or threaten part of this great biological richness. They also affect the ecological processes on which this richness depends and forms part.

During the 1995-2000 administration, the Environmental Program incorporated the Gulf of California as a priority area of marine resources and coastal ecosystems. Among the strategies proposed for the environmental protection of coastal areas, guidelines were established for environmental management that would allow harmonizing economic development with the use of natural resources. Special emphasis was also placed on promoting the generation and integration of information on coastal areas and ecosystems with the aim of having solid technical assistance that would support decision making for resources management in the Gulf of California region. In addition, the 1995-2000 Fishing and Aquaculture Program mentions that environmental problems derive from fishing and aquatic activities in Mexico related to structural and operative deficiencies, social lag in the fishing population, and limitations of an organizational and technological nature, as well as in job attendance and training. These conditions have impacted production. Given that bays function as reproduction and maturation areas, the negative effects of trawling are magnified because it erodes the sea bottom and causes mortality of many species.

Faced with this situation, different actions have been orchestrated for the protection of species. These include studies for the technological development of fish excluder and other devices that are able to reduce the impact and the incidental catch in trawling and in general. Through strategies that tend to achieve sustainable development of the region's resources, the intent is to maintain the balance between human socioeconomic aspects and the natural components. The Natural Protected Areas (NPAs) are a basic instrument of environmental policies to preserve biodiversity and the ecological goods and 
services of the nation. They also function as generators of sustainable development. The decree to constitute a natural protected area represents the judicial infrastructure necessary for a change in the management relations of ecosystems and natural resources and for organizing local communities and relevant interests in favor of development. By August 1992, in Mexico, a total of 71 NPAs had been decreed: 10 biosphere reserves (BR), 12 special biosphere reserves, 44 national parks (NP), two protected areas for wild flora and fauna (PAFF), and three natural monuments (NM). According to a report by the National Commission for Natural Protected Areas (CONANP) [3], by 2008, at the federal level, 156 NPAs had been decreed. These were distributed in the following categories: $38 \mathrm{BR}, 68 \mathrm{NP}$, four NM, 31 PAFF, 17 sanctuaries, seven natural resources protected area, and one protected area to be reclassified. There are seven priority NPAs in the Gulf of California region: Upper Gulf of California and Colorado River Delta BR, Bahías de Loreto NP, Cabo Pulmo NP, Gulf of California islands PAFF, El Pinacate and Gran Desierto de Altar BR, Vizcaíno BR, and, recently Los Cirios Valley PAFF.

A consolidated system of natural protected areas in the Gulf of California region, orchestrated by management programs and equipped with the necessary personnel for effective operations, will ensure an adequate promotion of these areas. The system will also allow establishing a link between conservation and development through jobs, revenues, and financing for the management and strengthening of conservation activities, both conventional as well as in their ecological modality. In addition to strengthening the coordination of the three levels of government, a consolidated system will harmonize policies and regulatory outlines among municipalities, states, and the federal government. The system will also result in new forms of participation and co-responsibility of the different sectors of the local, regional, and national society as these sectors concur in its management and administration. The future management of NPAs shows good prospects. This is because the Mexican government has assumed the responsibility by establishing different instruments of environmental policies that include Environmental Programs, Natural Protected Areas Programs, and the 2001-2006 Hydraulic Program. The latter integrated strategies based on regional analyses of Mexico's different hydrological, economic, social, and environmental characteristics. It also analyzed the characteristics of water supply and demand to determine and propose this resource's tapping policies that would facilitate the population's access to a higher standard of living. In addition, this program focused, through adequate water management, on a sustainable economic growth to stop current deterioration, care for the hydrological system from a quantity and quality perspective, and make the most of this resource in a full and sustainable way in agricultural, domestic, and industrial, activities; the generation of electrical energy; tourism; aquaculture; fisheries; and navigation.

The 2001-2006 Environmental Program emphasized that the Ecological Ordinance (land use planning process), in its modality or scale, must be the basis in determining the density and intensity of activities and ways of land use, as well as the areas to be preserved and restored. This planning instrument, in addition to being technically sound, must have agreement and consensus among 
government agencies, social groups, and production groups. It must contain the means and mechanisms to make its orientations possible; it must be expressed in local- incidence legislation; it must favour long-term certitude; and it must consider mechanisms to prevent environmental conflicts. According to modifications made to the General Law of Ecological Equilibrium and Environmental Protection (D.O.F, 1996)[5], the marine ecological ordinance was established to regulate productive activities in the exclusive economic area, including adjacent federal zones (Art. 20, BIS 6). Also established was compliance by the public administration in all government areas with this planning. In addition, it was determined a function of the then Secretariat of Environment, Natural Resources, and Fisheries (now SEMARNAT), through the National Ecology Institute (Inner Regulation of SEMARNAP 1996), to develop the territory's ecological ordinance in coordination with agencies and entities of the corresponding Federal Public Administration, with federal and municipal governments, and with the participation of social and private sectors. When the marine ecological ordinance for the Gulf of California was identified as a priority, and setting as a purpose: Establish a regulatory and coordination framework for activities developed in the territorial seas of the Gulf of California.

To date, regulation of this area is responsibility of the federal executive through its different sectors and without an express coordination; Give coherence to the territory's institutional or administrative and management policies, especially regarding the coordination among different government agencies; Simplify the application of other environmental policy instruments such as issuing licenses and permits, granting concessions in the federal terrestrialmaritime zone, and evaluating impact; Reconcile, upon one information platform, the interests of conservation and growth of the promotion sectors' programs (tourism, agriculture, urban development, aquaculture, fisheries, maritime transportation); Visualize in one single instrument the spatial distribution of programs and actions that are carried out in the territory, offering a framework of reference for follow-up and evaluation of the management of natural resources; Strengthen the application of other instruments and programs on environmental policies of a territorial nature, such as the Natural Protected Areas (NPAs); Mexican Official Norms (NOM), protection of wetlands, protection of habitats for species with status; Global Change, and Agenda 21, among others. This project is closely coordinated and linked to programs and actions that SEMARNAT develops within the Gulf of California region, particularly with the Management Program of the Archipelagos of the Gulf of California Islands Reserve, who contributes with elements, within an international context, for the implementation of the Global Program of Action for the Protection of the Marine Environment from Land-Based Activities, PNUMA, which establishes the need for inventories of point source and nonpoint source marine pollution: Prioritize the region's research needs; Identify and involve the Gulf of California or Sea of Cortés actors; Develop new actions with the necessary intensity in order to have a planning strategy that facilitates 
the direction of the region's productive activities toward a sustainable development.

The Territorial Ecological Ordinance (TEO) has been designed as a fundamental instrument that establishes environmental legislation to regulate the use of the land and productive activities - according to the availability of the country's natural resources - in order to preserve and restore the ecological balance and to protect the environment. The TEO is also the reference framework for the design of specific development programs. These programs incorporate policies, actions, and projects that propitiate consensus and coordinated investment of the public, social, and private spending, since the TEO is of a regional and intersectorial nature. It also analyzes the current state of natural resources and foresees alternative scenarios from current tendencies and process transformations, and provides the necessary elements to propose alternative resource uses from a sustainable perspective. The strategy established by the federal government in the 2000-2006 National Development Plan defines environmental problems as the search for balance among economic, social, and environmental objectives, in such a way that environmental deterioration is contained at the same time that the national territory's planning is encouraged. The plan identifies the Gulf of California as a priority area with regard to marine resources and coastal ecosystems. The guidelines for environmental management are established among the strategies proposed for environmental protection of coastal zones. These guidelines allow the harmonization of economic development with the use of natural resources. As mentioned earlier, the objective is to generate and integrate scientific and technical information on coastal zones and ecosystems with the aim of having solid technical assistance that supports decision making for resources management. Due to the ecological and economical importance of the region, it is necessary to organize both marine and land activities that take place in the territory. Currently, these activities are developed without long-term planning and their impacts overlap and environmentally degrade the ecosystems. They also limit in a significant way the possibility of promoting alternative development. So, following the current tendencies in the zone, it is necessary to delimit and define the activities that can be carried out in it. The "Escalera Náutica del Golfo de California" project, promoted by FONATUR since 2002 an from 2006 is called "Mar de Cortés Project", involves a variable number of locations distributed along the coastal areas of the Mexican states of Baja California, Baja California Sur, Sonora, and Sinaloa. If environmental considerations are not taken into account under the conceptual umbrella of sustainable development, this project can increase deterioration tendencies, conflicts over natural resources, and social inequalities in the region.

Since 1997, SEMARNAT has promoted the execution of several environmental planning instruments in the gulf region. The great importance of this region at a national level is due to its biological diversity, as well as its experiences in the conservation and management of natural resources. As part of these efforts, the first Marine Ecological Ordinance was developed in Mexico, in the Gulf of California region, as well as the Regional Ecological Ordinance of 
Mexico's northwest. The latter incorporates the marine ordinance within a regional context and includes the marine area of the Pacific and the hydrographic basins in a regional vision. That ecological ordinance is the regional framework from which the priority focus areas derive. Detailed studies will be developed in these areas without losing the regional context. In addition, there are six ecological ordinances in the region that have been decreed (Baja California state, Tijuana-Ensenada corridor, San Felipe-Puertecitos corridor, Bufadora-Punta Banda, Los Cabos corridor, and Los Cabos municipal) and 15 at different progress stages. Ten of the 15 are technically finished, but most have dated information and methodological approaches that are different from those currently used by SEMARNAT, which makes their management more difficult. The 10 decrees are made up of Bahía de San Francisco, Loreto-Nopoló, centralnorth coast of Sinaloa, south coast of Sonora, Municipality of Ensenada, Sinaloa state, Sonora state, Estero El Sábalo, Puerto Peñasco, and Puerto San Carlos. The remaining five (Sinaloa coast, Bahía de La Paz, Municipality of Loreto, Municipality of Hermosillo, and the community of Conca'ac) are at different development phases. All are supported by SEMARNAT and directly carried out by local institutions. Since 2002, SEMARNAT - through the National Institute of Ecology (INE), dedicated itself to propose local models for territorial ecological ordinances that would regulate and encourage land use and productive activities in the areas of interest. These models would be under a productivediversification outline with specific guidelines for the management of natural resources. Their perspective would be one of compatibility between the use, conservation, and protection of natural resources and an increase in the local population's quality of life. They would also consider the possibility of carrying out major investment projects, such as the Escalera Náutica (INE 2002). Within this context, the studies that INE proposed were developed since 2002 on a scale of 1:25,000 in the priority focus areas of the Escalera Náutica project and, since 2003 , on a finer scale (which could be 1:10,000 or 1:12,000) for explicitly defined areas in this project. These places were defined by mutual agreement between FONATUR and INE and will address social and economic components, at least at the local level (Figure 1).

The analysis of the landscape's suitability and potential defines its possibility of exploitation, which is known as environmental supply. This supply must be delimited and confronted with the current and foreseen social demand under different scenarios of economic growth and investment in the region. Thus, it will be possible to define the territory's management and use guidelines over the medium and long term, INE [4]. The outline proposed in these studies is one of participative planning. It attempts to involve the main local actors, with special emphasis on the municipal actors, since there is a working history with other sectors of society in each of the aforementioned localities. The goal of this planning process is to inform the population of the current status and problems that it faces with regard to the natural resources that it uses daily. It will also present to the population the proposals to achieve a sustainable use of the territory's natural resources in this complex and important area of the Gulf of California. 


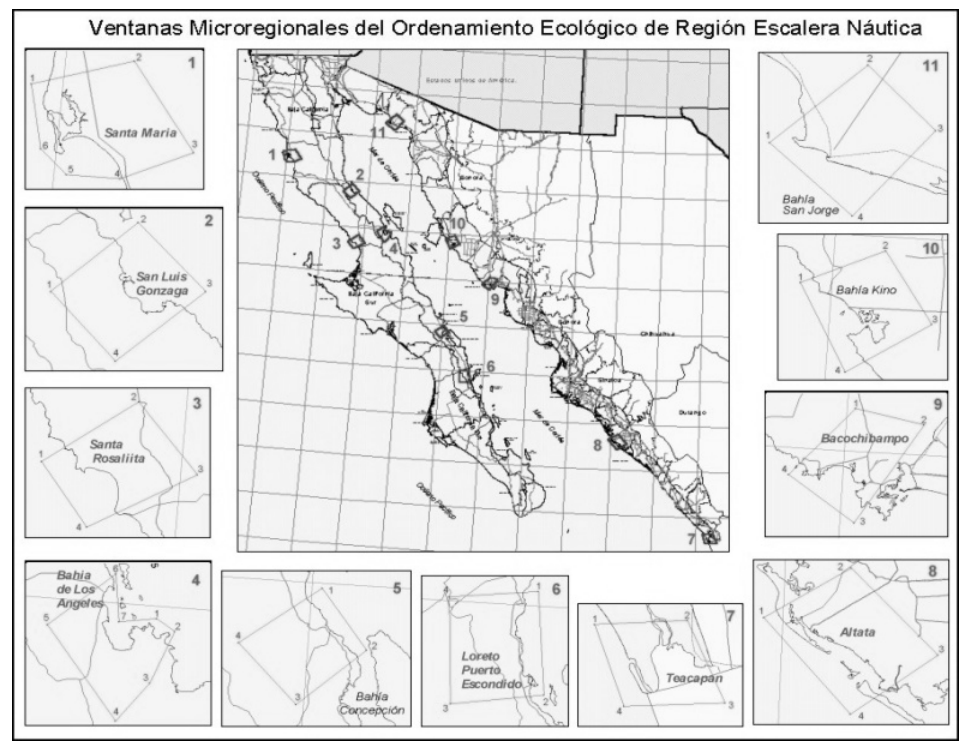

Figure 1: $\quad$ Location of Microregions. (Source: INE 2002.)

The Marine Ecological Ordinance of all the Gulf of California began on the 5 th of June of 2004 with the subscription of the Coordination Agreement between the Federal Government (represented by the six ministers of state: SEMARNAT, SAGARPA, SEGOB, SEMAR, SECTUR and SCT) and the five governments of the coastal states, Baja California, Baja California Sur, Nayarit, Sinaloa and Sonora, and concluded with the publication of the Ordinance in the Official Diary of the Federation (DOF) in December of 2006. For each one of the 22 microregions identified in the Gulf (named UGAs - seven were oceanic and 15 were coastal zones - presented in fig. 2, a proposal was finally elaborated, taking into account regulations and criteria, that conform the base for its management.

From 2007, several meetings and actions regarding the Ordinance of the region process have been taking place in the different states of the Gulf, with all the productive and social sectors involved, with very good results until the 2009.

Finally, an instrument that recently has been integrated into the Ordinance process, is the one called "National Environmental Policy for the Sustainable Development in Oceans and Coasts", its mission is to produce an administrative framework that serves as a link between the economic sectors and the different governmental departments, in order to generate actions of integrated management with a base in the perspective of ecosystems. In this it is established an strategy and regulations of public policy that look for strengthening the environmental management of the coastal zone in an integral way in all Mexico, aided by an structural reform, an effective institutional reform, and a wide social participation. 


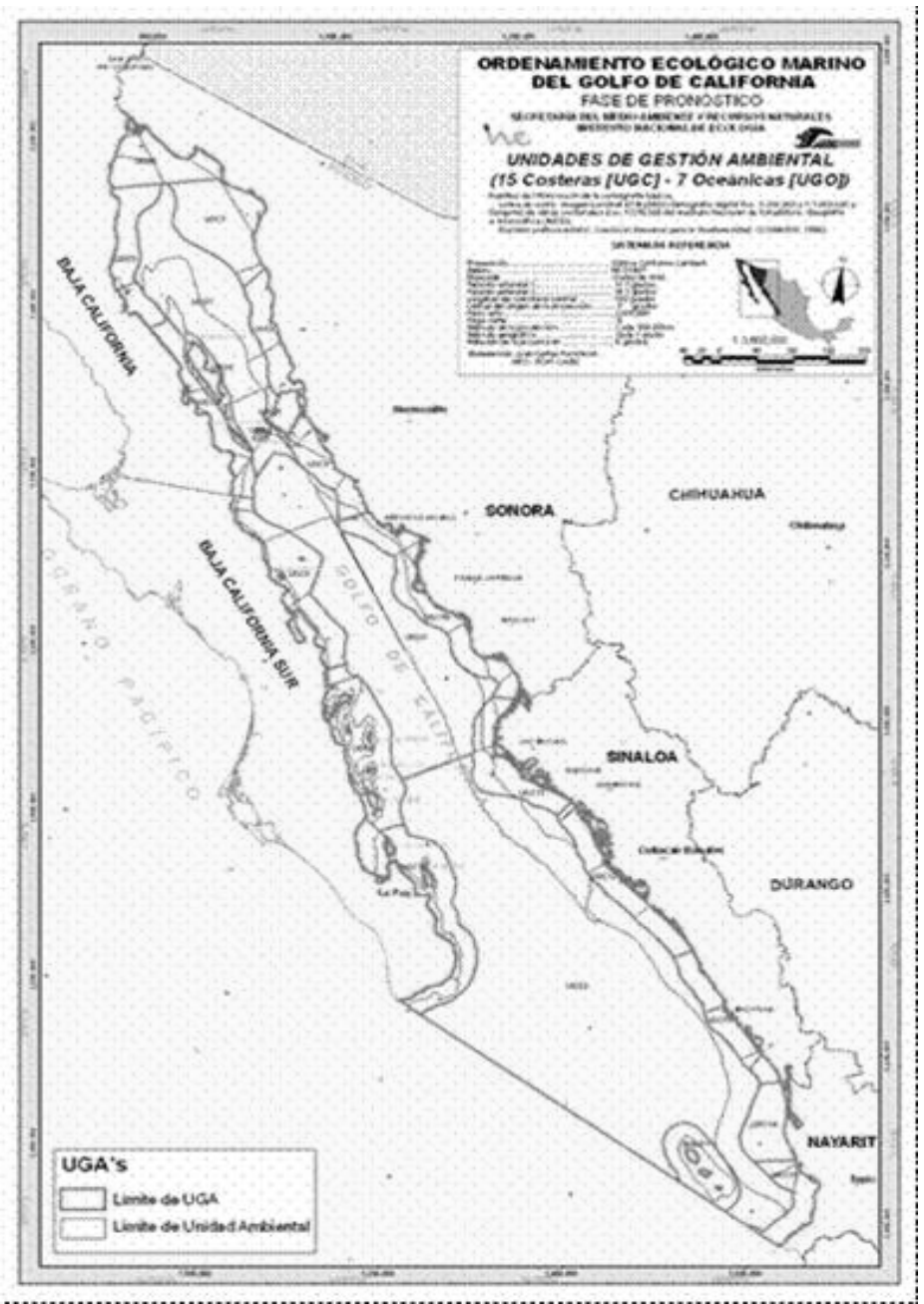

Figure 2: $\quad$ Management units (22) in the Gulf of California.

This Environmental Policy guides the design, development and maintenance of a system of actions and decisions of the different levels of government, based in the continual exercise of participative planning with the population and economic agents with an interest in the coastal zones, in order to seek a sustainable development, expressed in the security of ecosystems, the protection of its inhabitants and its economic and social development. Diario Oficial de la Federación (DOF) [5]. 


\section{References}

[1] Nebel, B. and R. Wright, 1999. Ciencias Ambientales (Ecologia y Desarrollo Sostenible). Prentice Hall. Ed. Pearson. México.

[2] Poder Ejecutivo Federal. 2001. Plan Nacional de Desarrollo 2001- 2006. Presidencia de la República-Poder Ejecutivo Federal. México.

[3] CONANP 2007. Programa Nacional de Areas Naturales Protegidas 20072012. SEMARNAT, México.

[4] INE - SEMARNAT 2000. El ordenamiento ecológico: Logros y retos para el desarrollo sustentable 1995-2000. INE, México.

[5] Diario Oficial de la Federación 1988. Ley General del Equilibrio Ecológico y la Protección al Ambiente, 28 de enero de 1988. 